\title{
Smartphone Application Development for Rice Field Management Through Aerial Imagery and Normalised Difference Vegetation Index (NDVI) Analysis
}

\author{
Nor Athirah Roslin ${ }^{1}$, Nik Norasma Che'Ya ${ }^{1 *}$, Rhushalshafira Rosle ${ }^{1}$ and Mohd \\ Razi Ismail ${ }^{2}$
}

${ }^{1}$ Department of Agriculture Technology, Faculty of Agriculture, Universiti Putra Malaysia, 43400 UPM, Serdang, Selangor, Malaysia

${ }^{2}$ Department of Crop Science, Faculty of Agriculture, University Putra Malaysia, 43400 UPM, Serdang, Selangor, Malaysia

\begin{abstract}
In the current practices, farmers typically rely on the traditional method paper-based for farming data records, which leads to human error. However, the paper-based system can be improved by the mobile app technology to ease the farmers acquiring farm data as all of the farm information will be stored in digital form. This study aimed to develop a smartphone agricultural management app known as Padi2U and implement User Acceptance Test (UAT) for end-users. Padi2U was developed using Master App Builder software and integration with the multispectral imagery. Padi2U provides recommendations based on the Department of Agriculture's

ARTICLE INFO

Article history:

Received: 2 November 2020

Accepted: 10 February 2021

Published: 30 April 2021

DOI: https://doi.org/10.47836/pjst.29.2.07

E-mail addresses:

norathirahroslin@gmail.com (Nor Athirah Roslin)

niknorasma@upm.edu.my (Nik Norasma Che’Ya)

rhushalshafira.rosle@gmail.com (Rhushalshafira Rosle)

razi@upm.edu.my (Mohd Razi Ismail)

*Corresponding author

(DOA), such as rice check, pest and disease control, and weed management. Through the Padi2U, farmers can access the field data to understand the crop health status online using the Normalised Difference Vegetation Index (NDVI) map derived from the multispectral images. The NDVI is correlated to the Soil Plant Analysis Development (SPAD) value, corresponding to $\mathrm{R}^{2}=0.4012$. UAT results showed a 100 percent satisfaction score with suggestions
\end{abstract}


were given to enhance the Padi2U performance. It shows that Padi2U can be improved to help farmers in the field monitoring virtually by integrating multispectral imagery and information from the field.

Keywords: Chlorophyll content analysis; multispectral imagery; smart farming; smartphone application

\section{INTRODUCTION}

Agriculture is one of Malaysia's most significant sectors as it contributes to the country's economy. Smart farming is the idea of enhancing farm management by implementing technology as part of routine farming activities (Muangprathub et al., 2019). For instance, the application of the Internet of Things (IoT) (Jaiganesh et al., 2017) in smart agriculture would provide information on farm management in terms of plant and pest control based on the data collected from the site (Khanna \& Kaur, 2019). A significant aspect of agricultural management is the monitoring of crop growth and output during the developmental stages. It helps the farmer to introduce timely measures at the end of the season that ensure maximum yields. In addition to ensuring successful farm management through the smart farming system, the inclusion of technology in agriculture has been shown to save costs by agronomists (Sushanth \& Sujatha, 2018). In the agricultural sector, agricultural innovations have been used to assist farmers in their farm management, such as image analysis (Razali et al., 2009; Hudzari et al., 2010; Ishak \& Hudzari et al., 2010), Unmanned Aerial Vehicle (UAV) technology (Liu et al., 2018), sensor technology (Nam et al., 2017), Global Navigation Satellite System (GNSS) (Guo et al., 2018), GIS (Zhang \& Cao, 2019), and smartphone application technology (Bueno-Delgado et al., 2016). These innovations have been developed to help farmers track and control their crops at home or in the workplace. UAV, for example, is useful for monitoring the entire plantation whereby the farmer may individually observe and examine the crop (Abdullah et al., 2019). In addition, the smartphone app is also useful in introducing farmers to digital agriculture in which farmers can obtain information about crops and manage their field according to the crop status.

The Normalized Difference Vegetation Index (NDVI) created by multispectral UAV is a plant health indicator that is used to quantify the condition of vegetation in order to assess plant germination and its productivity (Rosle et al., 2019). NDVI values vary from -1 to 1 , whereby -1 means non-living things, while 1 applies to living things (Christensen, 2019). Furthermore, it has been used to determine crop health status via the detection of chlorophyll content in the crop (Rosle et al., 2019). Smartphone apps have been widely used for different functions in agricultural management. For paddy, the existing system uses the Internet of Things (IoT) and smartphone technology for field management (Kularbphettong et al., 2019). Online at Sawah application shows high acceptance by the users as it is 
efficient, easy to learn and satisfactory to use (Simorangkir et al., 2018). Another mobile app, Aptani (Siahaan \& Wijaya, 2018) was tailor-made for farmers to provide planting techniques of paddy and methods of controlling pests and diseases in paddy. An automated irrigation system for paddy was also developed in a smartphone app (Barkunan et al., 2019). I-PEDIA is an app developed to identify paddy diseases (Majid et al., 2013). SmartSPAD is another app used in agriculture and it estimates the chlorophyll content (Vesali et al., 2015). Insect Shot is an app that can monitor the brown planthoppers in the paddy field (Watcharabutsarakham et al., 2016). Table 1 shows a summary of the mobile application for agriculture. Based on our review and knowledge, most of the agriculture apps developed limited to one crop management element compared to Padi2U app developed consists of all elements in crop management.

On the other hand, crop monitoring and management will be very useful from the multispectral imagery UAV that can be generated NDVI analysis for health status in the field. Ideally, trends in the future are crop monitoring using IoT and smartphone is one of the common platforms for everyone that can help farmers monitor the crop in an effective way. Thus, this study's objectives were to develop a smartphone app known as Padi2U for agriculture and analyse the relationship between Normalised Difference Vegetation Index (NDVI) generated from UAV and chlorophyll content measured by Soil Plant Analysis Development (SPAD) meter at the ground.

Paddy (Oryza sativa) is one of the main crops in Malaysia's agriculture sector (Hassan et al., 2019) and grows rice in this country for stable food. Depending on environmental factors and paddy variety, the complete paddy growth cycle is 120-150 days (Yuzugullu et al.). The paddy growth begins with the flooding of paddy fields for a few weeks before the paddy is transplanted onto the field (Yuzugullu et al., 2017). The first stage of paddy growth is vegetation, whereby germination occurs to initiate the panicle formation (Yuzugullu et al., 2017). The paddy production enters the second stage, the reproductive phase when the panicle successfully forms from the tiller base. At this phase, flowering begins and it enters the stage of maturation (Yuzugullu et al., 2017). Grain filing is done at the ripening stage and excess water in the field is drained to facilitate the harvesting process (Yuzugullu et al., 2017). With total plantation areas of 686,050 hectares, paddy is the most planted crop in Malaysia. Nevertheless, its production is low (Hassan et al., 2017), likely due to the limited amount of fertiliser used (Fatah et al., 2017), excessive pesticide usage (Fatah et al., 2017), climate change (Alam et al., 2019), ineffective irrigation system (Ibrahim \& Alam, 2016), Inappropriate technology practice (Hassan et al., 2019), poor farm management (Norasma et al., 2019), unsatisfactory soil conditions (Yusof et al., 2019), disease and pest outbreaks (Yusof et al., 2019) and the output of farmers (Yusof et al., 2019; Alam et al., 2019). Such circumstances cause Malaysia's rice sector to be at a critical point. As a result, to satisfy local demand, Malaysia still needs to import rice from other countries, such as Thailand 
and Vietnam. Such circumstances cause Malaysia's rice sector to be at a critical point. As a result, to satisfy local demand, Malaysia still needs to import rice from other countries, such as Thailand and Vietnam.

It is difficult for many rice farmers to conduct crop monitoring and sampling, soil testing, and maintenance of equipment in the paddy sector. In current practice, farmers usually rely on paper-based records to keep all the field data, which is inconvenient as it can be time-consuming for the farmers, subsequently lead to poor management. The optimum planting time is also difficult to predict, apart from tackling any pests and diseases in the plantation (Fountas et al., 2015).

Table 1

Mobile application function and type of crop

\begin{tabular}{lll}
\hline Mobile Application & Crop & References \\
\hline Diagnose disease & Cassava & Mwebaze and Owomugisha (2016) \\
& Coffee & Manso et al. (2019) \\
& Tobacco & Valdez-Morones et al. (2018) \\
& Corn & Simorangkir et al. (2018) \\
& Paddy & Nasir et al. (2018) \\
Pest monitoring & Paddy & Watcharabutsarakham et al. (2016) \\
Field management & Paddy & Kularbphettong et al. (2019) \\
Planting technique & Paddy & Siahaan and Wijaya (2018) \\
Irrigation system & Paddy & Barkunan et al. (2019) \\
Chlorophyll content & Corn & Vesali et al. (2015) \\
measurement & & \\
\hline
\end{tabular}

\section{MATERIAL AND METHODS}

The study area located at Ladang Merdeka, Kampung Lundang Paku, Ketereh, Kelantan, Malaysia with total area 20 acres (Figure 1). Rice variety planted at this site known as PadiU Putra developed by Universiti Putra Malaysia (UPM) researcher. This paddy variety resistance to leaf blight disease was planted by broadcasting on 30th January 2019.

\section{Data Acquisition}

Image Acquisition. Aerial imagery was collected using a DJI Phantom (Shenzhen DJI Sciences and Technologies Ltd., Guangzhou, China) and a multirotor UAV, XR q350 pro mounted with multispectral sensor Parrot Sequoia (Parrot, France, Paris) (Figure 2). 




Figure 1. Paddy plot study at Ladang Merdeka, Ketereh, Kelantan.

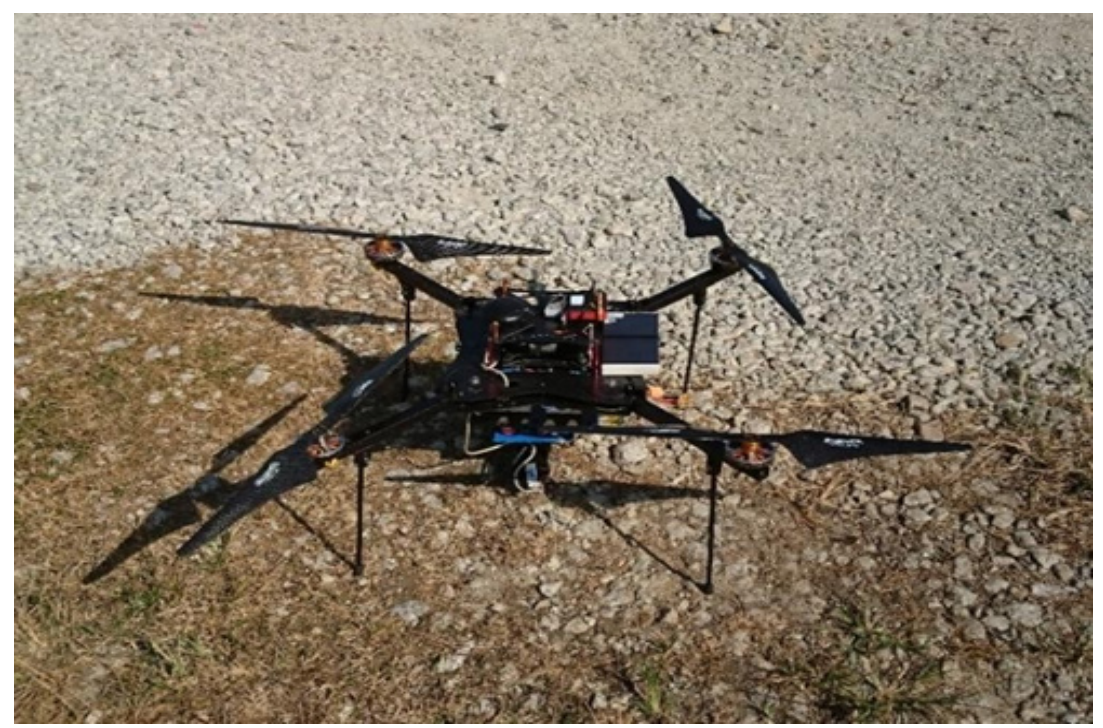

Figure 2. A multirotor UAV, XR q350 pro. 
The flight altitude was $70 \mathrm{~m}$ with a $2.13 \mathrm{~cm} /$ pix of spatial resolution. Aerial images were collected for different paddy growth stages starting at 12 Day After Planting (DAP), 23 DAP, 36 DAP, 55 DAP, 69 DAP, 75 DAP, 94 DAP, 104 DAP, and 118 DAP (Figure 3).

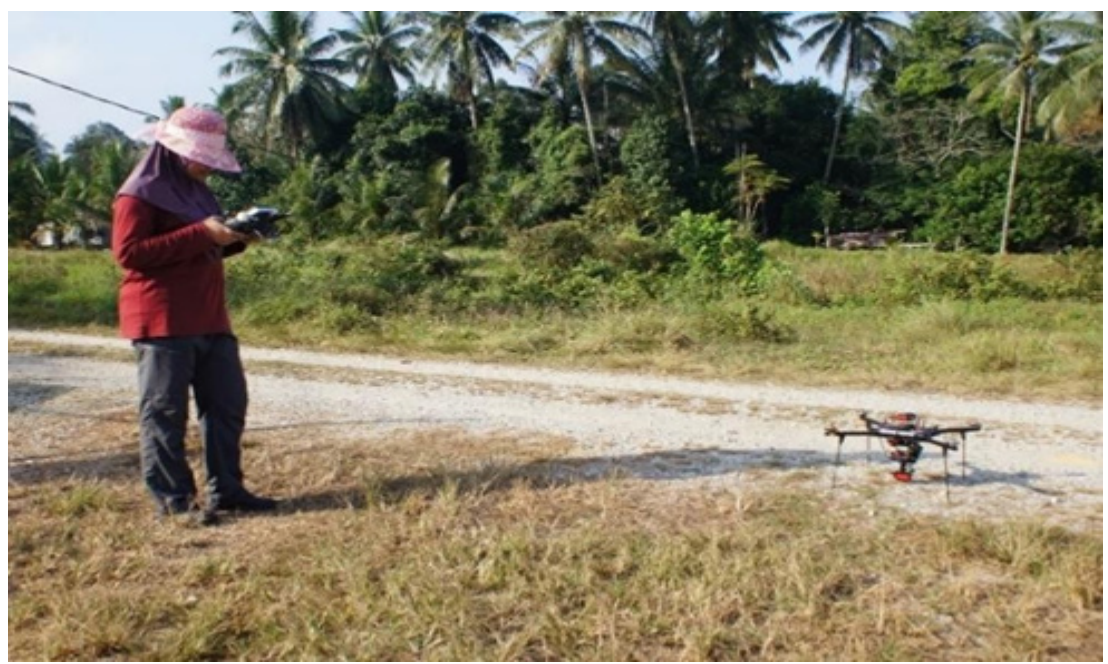

Figure 3. A pilot controlled the UAV with remote control from ground.

Ground Control Point (GCP) was placed at the corner of the paddy field for the georeferencing process (Figure 4). Before fly the UAV, the sensor was calibrated using white panel references provided by the Parrot Sequoia. Data collection was conducted in the morning from 8:30 am to 11:00 am.

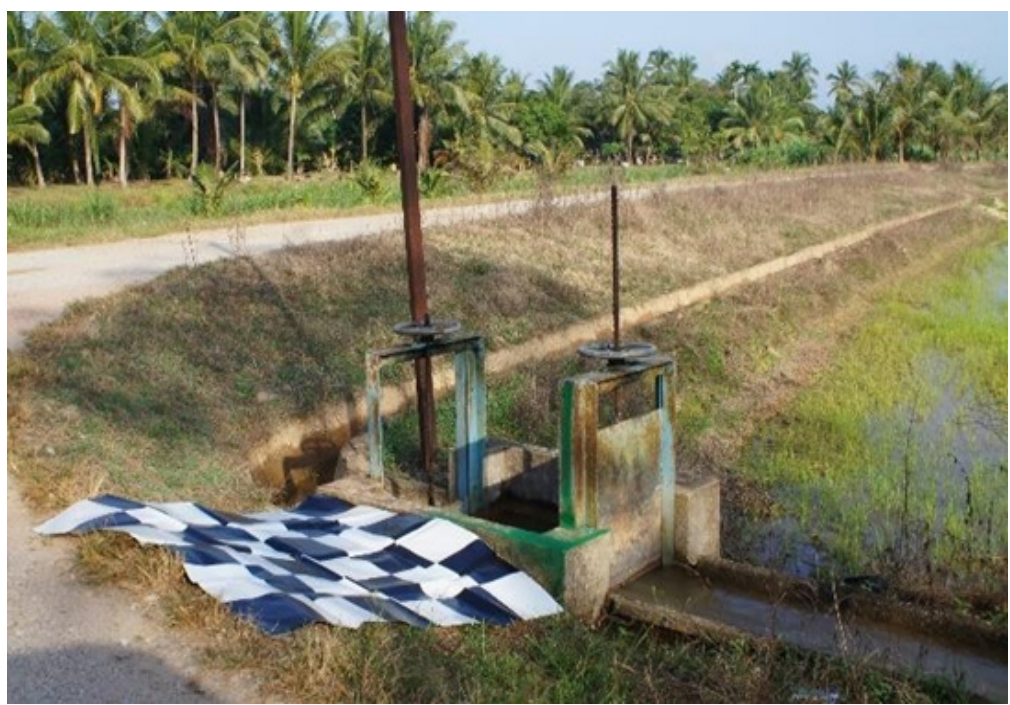

Figure 4. The GCP placed at the corner of the paddy field. 


\section{Chlorophyll Concentration Measurement}

The leaf chlorophyll concentration measured on fully expand leaf by using a hand-held device known as SPAD-502 meter (Konica Minolta Sensing, Inc., Osaka, Japan) based on the leaf transmittance wavelength measurement for red $(650 \mathrm{~nm})$ and infrared $(940 \mathrm{~nm})$. This device used to measure the concentration of the chlorophyll in leaf in the safest way and without causing destruction to the leaf sample. The SPAD meter reading was taken at the midpoint of the leaf. Ten SPAD meter readings at each points were averaged to represent the mean SPAD readings. The ground data collection began on 22nd February 2019 (23 DAP), 7th March 2019 (36 DAP) and 26th March 2019 (55 DAP) (Figure 5).

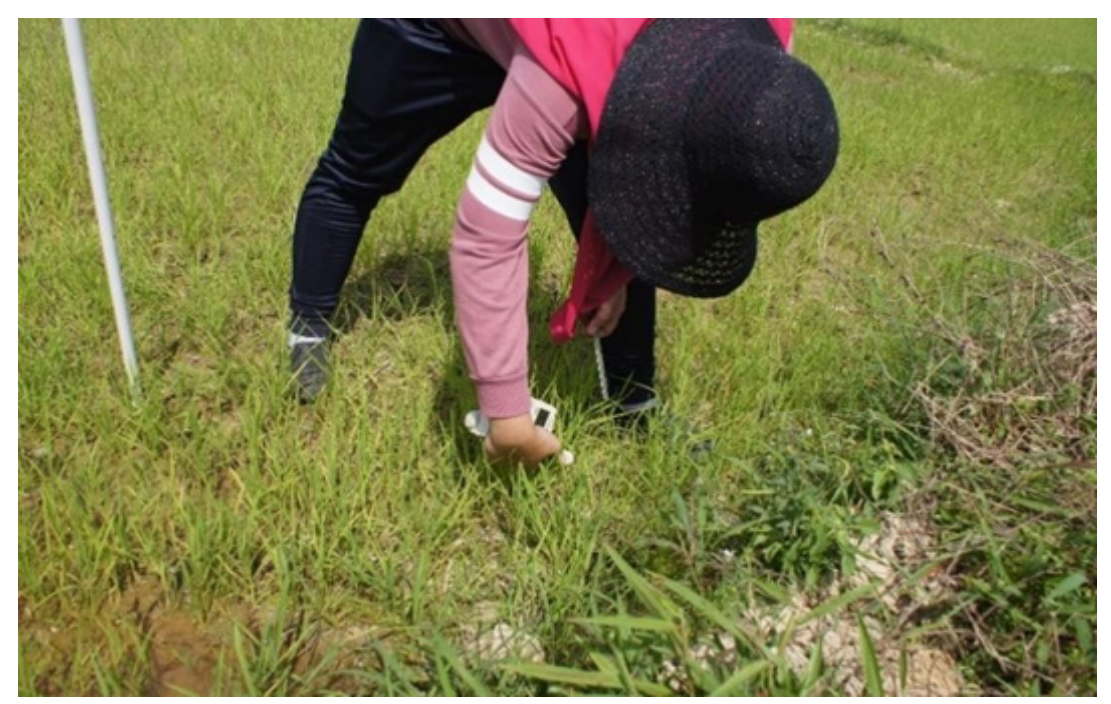

Figure 5. Ground data collection process.

There were eight polyvinyl chloride (PVC) poles about 1 meter height were placed randomly at eight different location around the paddy field area (Figure 6).

Eight points were marked to collect the ground data and at each points ten readings were measured and recorded by using the SPAD-502 meter (Figure 7). The ten leaves sample were taken within 1 meter radius from the PVC poles. The SPAD data collection point were made based on NDVI classification representing the different ranges in its value. The points were used to validate the NDVI value, which had represented the features in the study area. However, due to time constraints and limited human resources and equipment, the study only managed to collect a small number of SPAD data. Therefore, for future research, it is advisable to increase the number of SPAD data to increase accuracy. 


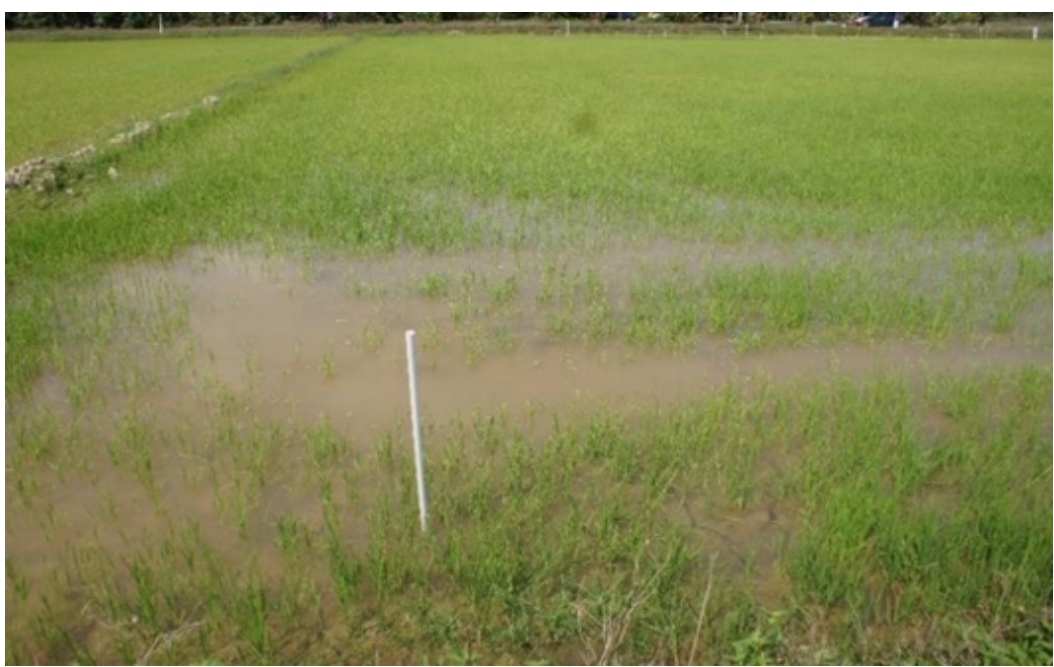

Figure 6. The PVC pole use as marker for ground data collection.

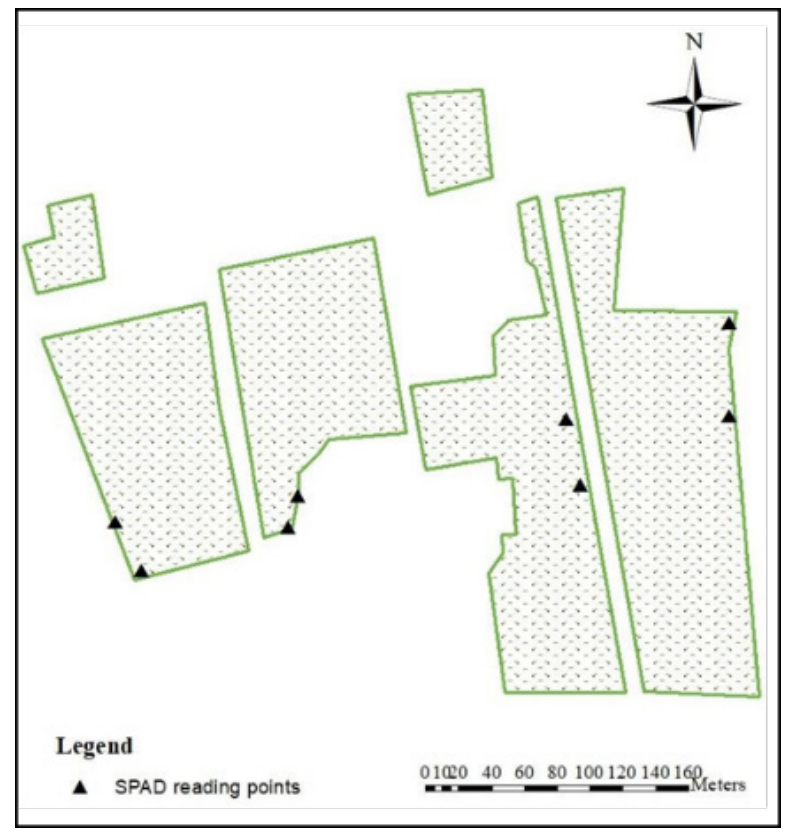

Figure 7. Eight points marked on the map for chlorophyll content data collection.

The ground images captured with high-resolution Canon camera PowerShot SX260 HS (Canon, Japan, Tokyo) (Figure 8). 


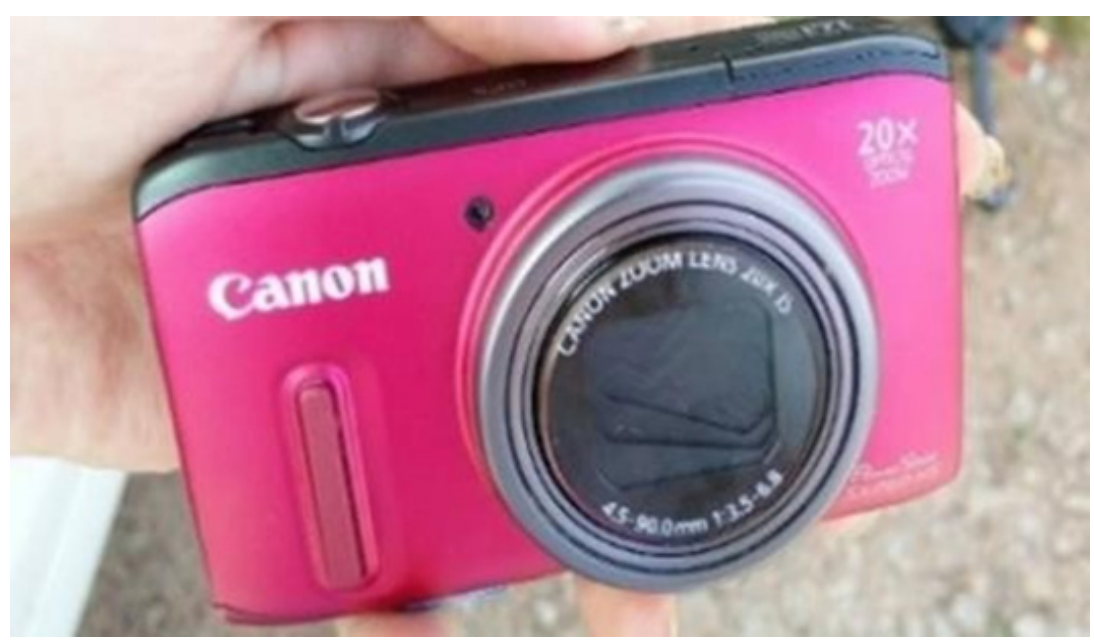

Figure 8. Data collection for ground data images using Canon camera PowerShot SX260 HS (Canon, Japan, Tokyo).

\section{Image Processing}

Image processing process began with import all raw images into Agisoft Photoscan Profesional software (Agisoft LLC, St. Peterburg, Russia) for mosaic and align images to produce an orthomosaic image by using Structure from Motion (SfM) algorithm (Figure 9). The orthomosaic image was then processed in ArcGIS 10.1 software, Arc Map to calculate the vegetation index value and produce the map.

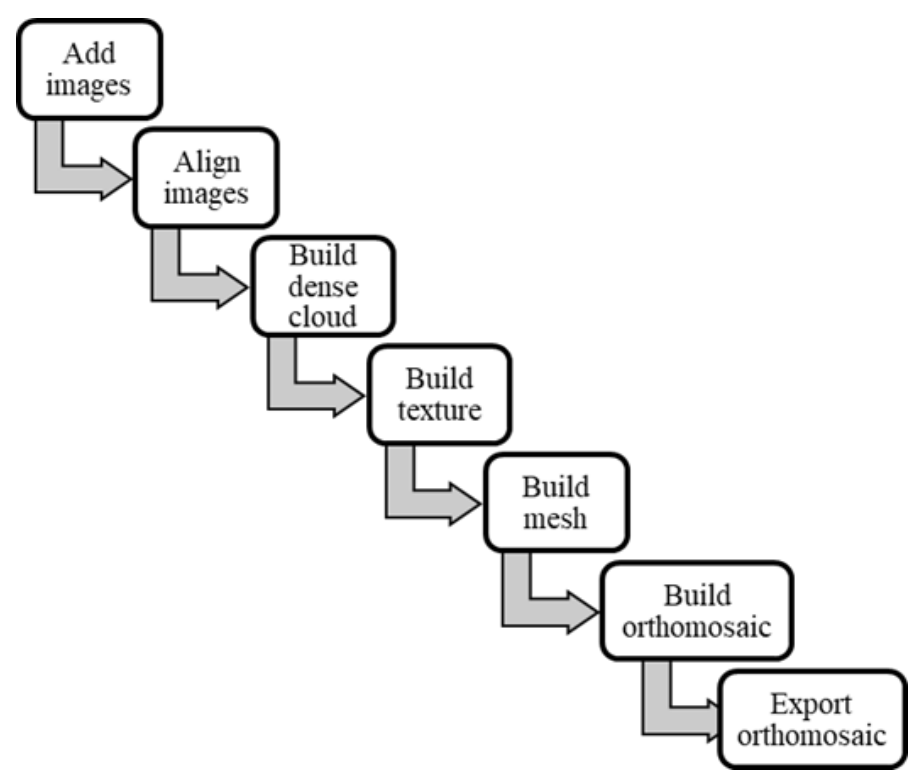

Figure 9. Image processing process in Agisoft Photoscan Profesional. 


\section{Data Analysis}

Vegetation Analysis for Different Vegetation Indices. NDVI is vegetation index was chosen to measure the crop health by using its algorithm formula (Equation 1). There are two bands used to calculate the NDVI value, Near Infrared (NIR) band (770-900 nm) and red band (630-690 $\mathrm{nm}$ ) based on the absorption in the red caused by the pigmented of chlorophyll and reflection in the infrared due to the structure of the leaf cellular. This NDVI calculation process conducted by using Arc Map software (Esri, California, USA).

$\mathrm{NDVI}=(\mathrm{NIR}-\mathrm{Red}) /(\mathrm{NIR}+\mathrm{Red})$

Where

NIR $=$ reflection value of near-infrared band

$\mathrm{RED}=$ reflection value of red range of the band

\section{Statistical Analysis between Vegetative Indices (NDVI/ NDRE/ SAVI/ OSAVI) with SPAD Readings}

The statistical analysis conducted using Microsoft Excel between vegetation index NDVI values from multispectral images analysis in ArcMap correlated with leaf chlorophyll concentration result obtained from the SPAD meter reading. The Pearson correlation analysis used to get the correlation analysis and regression value between the NDVI and chlorophyll concentration. The root mean square error (RMSE) was calculated to predict how dispersed the NDVI values from SPAD reading using Equation 2.

$$
R M S E=\sqrt{\frac{\sum_{i=1}^{N}\left(\text { Predicted }_{i}-\text { Actual }_{i}\right)^{2}}{N}}
$$

Where

Predicted $_{i}=$ The predicted value for the ith observation

Actual $_{i}=$ The observed (actual) value for the ith observation

$\mathrm{N}=$ Total number of observations

\section{Padi2U Mobile App Development}

The development of Padi2U involved four stages, namely early design phase, research design phase, research development phase, and research implementation phase.

Early Design Phase. The early design phase aimed to identify the problems faced by the farmers. They were found to have difficulties in finding information about their crop and farms. The information was scattered in many different platforms.

Research Design Phase. The research design phase designed the content of Padi2U. Based on the problems identified in the first phase, the content to be included was information of 
agriculture agency, variety of paddy, planting schedule, weather, site information, drone images including multispectral images and red green blue (RGB) images, pest and disease information, supplier contact information, and farmer report form.

Architecture of Padi2U Application. The architecture of Padi2U consisted of three layers: Presentation Layer, Business Layer, and Data Access Layer (Figure 10). In the Presentation Layer, users can view the Graphic User Interface (GUI) of Padi2U and make their decision based on listed examples of Paddy Disease on the menu. The Business Layer is where all the workflows of the app and the actual business of the app take place. Lastly, the Data Access Layer consists of data utilities and access and functions as the back end of the app. For example, if a user requests for disease information, the Business Layer will connect the user to the disease GUI. The database of the disease menu is stored in the Mobile Builder Apps located in Kuala Lumpur, Malaysia.

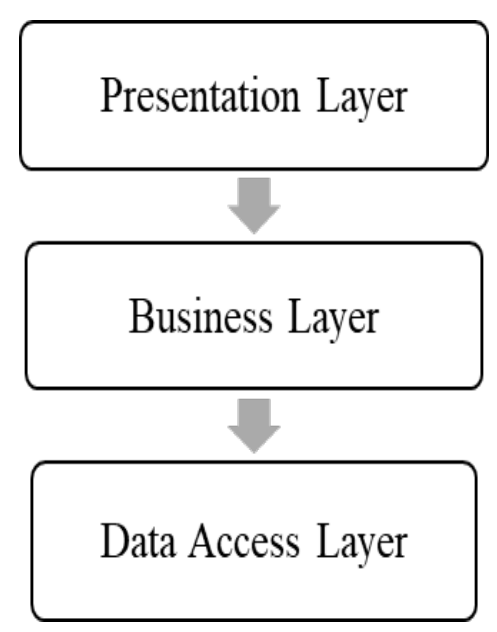

Figure 10. Architecture of Padi2U mobile app.

Padi2U App Menu. The menu and content in the Padi2U app (Figure 11).

Research Development Phase. This phase started with data collection followed by the installation process and system configuration. All the information were analysed and arranged in the database using the Master App Builder software (Malaysia, Kuala Lumpur). The menus were first created before the information was uploaded onto the menus according to the design. The information was in the form of text and images. All the imagery and analysis based on the multispectral and NDVI map were stored in the Padi2U database using Master App Builder software. 


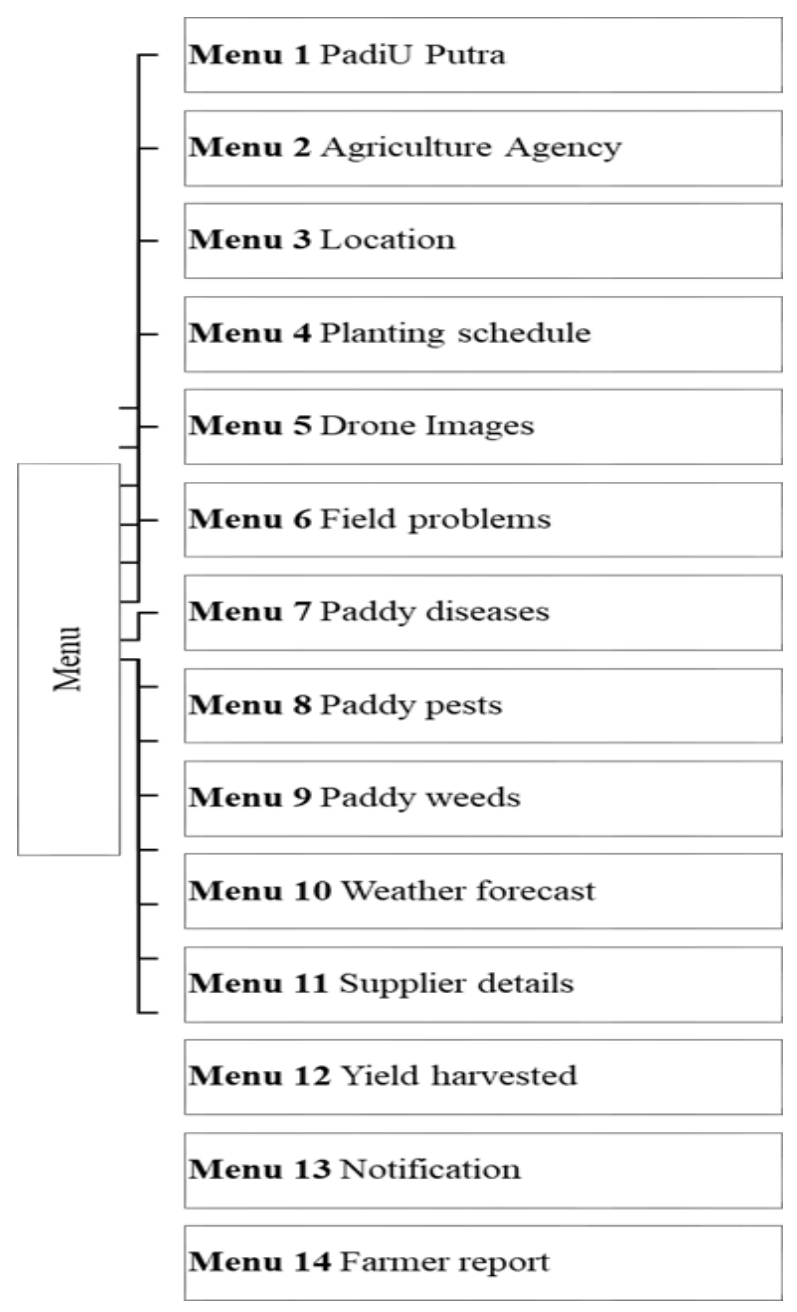

Figure 11. Padi2U app main menu.

Figure 12 shows the software of Master App Builder (Apps Master Builder, Malaysia, Kuala Lumpur) that contains the design of the mobile app, colours, and features. The developer chose one of the design that was suitable and easy to use. The features for the menu originated from a custom page where the text and images were uploaded according to the template. The features on the custom page could also be rearranged based on the content of the menu. For example, under the Drone Images menu and Field Problem menu, the feature chosen was Gallery because this menu could store a lot of pictures and it also enables the users to have a better view by zooming into the images. As for the weather menu, its features were designed specifically for the forecasting of weather. Next, the section on Supplier Information applied the contact information feature while Farmer Report used 
a form- based feature that allowed the users to fill in the form before submitting to the back end users. During the development process, the developers could view the app being developed by installing the previewer from the Google Play Store on their smartphone. By filling up the login information, the preview page would be able to show the developers how the app operated on the smartphone before being published.

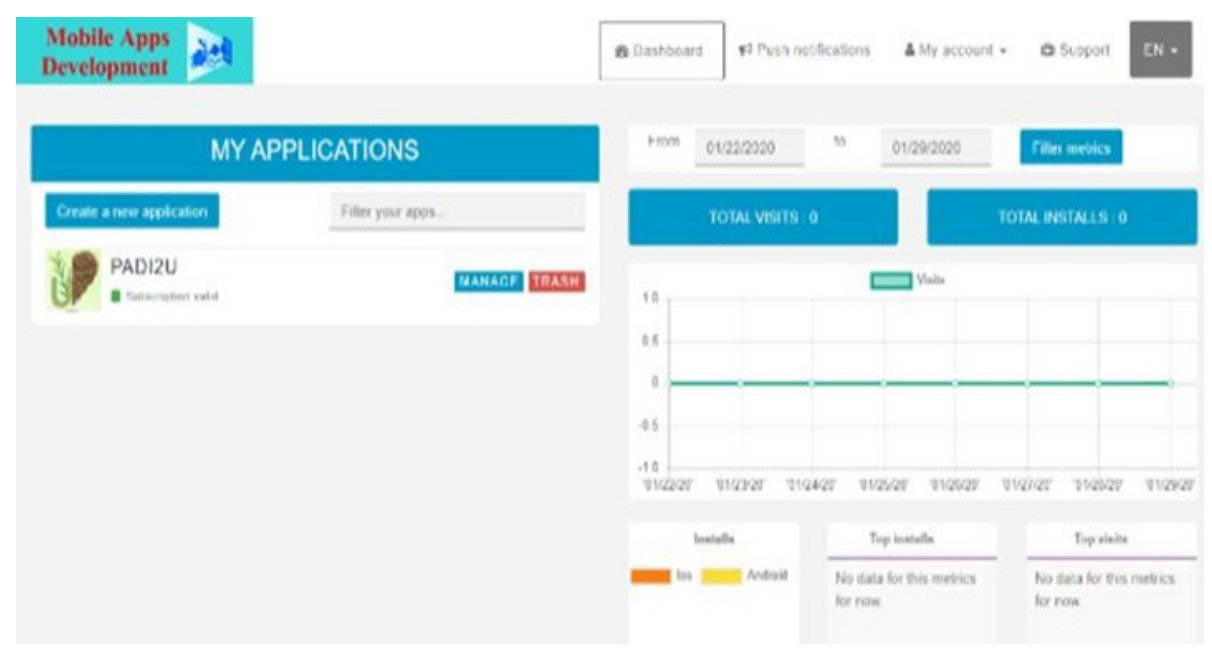

Figure 12. Mobile app development software, Master App Builder (MAB) (Apps Master Builder, Malaysia, Kuala Lumpur).

Research Implementation Phase. The final stage involved the research implementation in which all the functions in Padi2U were developed and tested on the users. Padi2U used Malay, the local language to enable a better understanding of the programme, especially among farmers.

User Acceptance Test (UAT). The UAT was conducted among 13 respondents at Pertubuhan Peladang Kawasan (PPK) Sungai Ketereh, Kelantan (Malaysia) (Figure 13). The respondents selected and decided by the agriculture officer of PPK Sungai Ketereh. Descriptive statistics was used to describe the socio demographic profiles of the respondents. The respondents consisted of farmers, agriculture officers, clerks, and students, and their age ranged from 19 years old to 40 years old. All of them were smartphone users with different operating systems, iOS, and Android. Most the respondents used the mobile app from their smartphones. They tried out the Padi2U app before answering the questionnaire. The questionnaire is divided into two parts, Part A and Part B. In Part A, the question more on respondents' details such as occupation, age, smartphone user, type of operating system, internet user, time spent using the smartphone, and preferable to use 
the website or mobile app from their smartphone. In Part B, the questions about the mobile app interface, the information in the app, and its performance. They were also encouraged to provide any recommendations to improve the app.

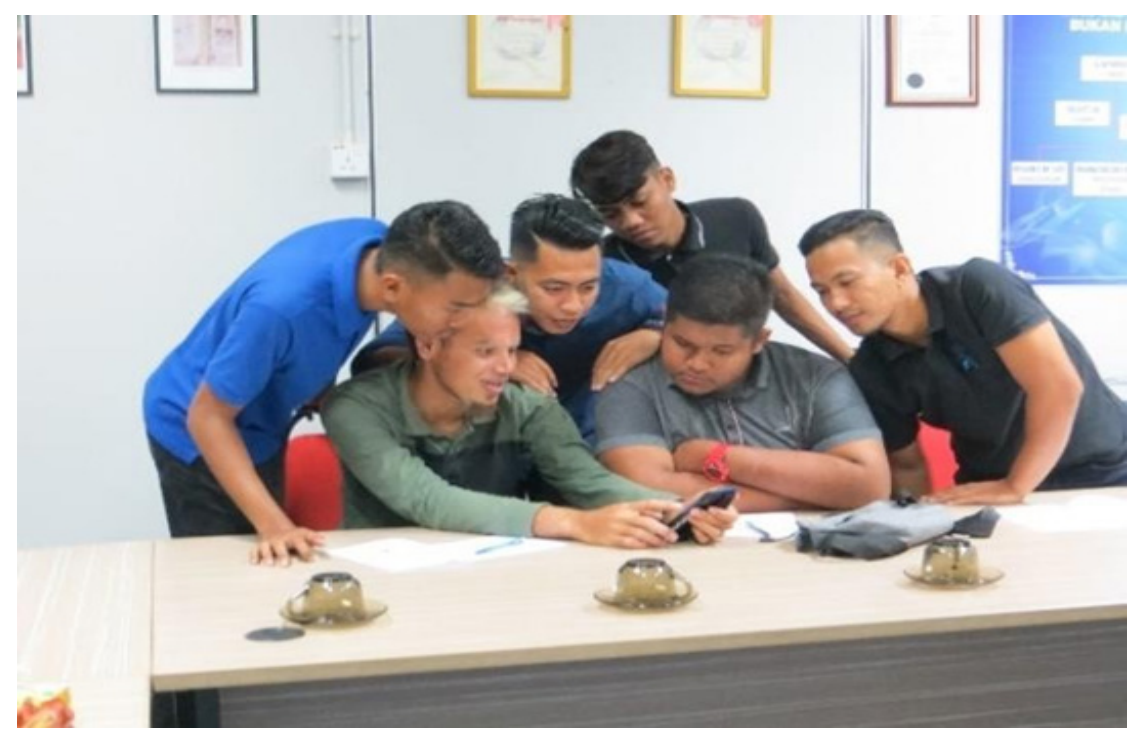

Figure 13. The respondents testing the Padi2U during UAT.

\section{RESULT AND DISCUSSION}

\section{Chlorophyll Content and Vegetation Index Analysis}

The average of SPAD readings and NDVI values shown in Table 2 shows data obtained from data collection on 22nd February 2018 (23 DAP), 7 Mac 2018 (36 DAP) and 27 Mac 2018 (55 DAP). The SPAD values are the measurement of chlorophyll concentration in the leaf measured by a hand- held and non-destructive device, SPAD 502 meter. The trend of SPAD values is increasing over the time from 23 DAP to 55 DAP (Table 2). This shows that the chlorophyll concentration is increasing and photosynthesis activity is increasing as the paddy plant grow into different growing stages (Liu et al., 2019). The NDVI values shows the lowest value at 23 DAP around 0.1 because at early rice growth stage, the canopy area of the paddy crops were small and the reflectance caused by the water and soil surface. The NDVI measurement is sensitive to the canopy structure and content of photosynthesis chemical (Gamon et al., 1995). The development of leaf canopy and the rate of photosynthesis were related (Gamon et al., 1995). However, NDVI increased as the plant growth at 36 DAP and 55 DAP. The increase value of NDVI is caused by the development of panicle on the top of the leaf canopy (Casanova et al., 1998). The increasing in value of NDVI is caused by the application of fertilizer and it is the management recommendation 
to apply fertilizer (Guan et al., 2019) after seeding stage and at the tillering stage (Casanova et al., 1998).

Table 2

The average of SPAD and NDVI values for 23 DAP, 36 DAP and 55 DAP

\begin{tabular}{lccc}
\hline & 23 DAP & 36 DAP & 55 DAP \\
\hline SPAD values & 17.41 & 25.38 & 37.49 \\
NDVI values & 0.10 & 0.39 & 0.58 \\
\hline
\end{tabular}

\section{Rice Growth Stages Relationship with SPAD and NDVI Value}

The values of SPAD increased as paddy growth into different stages (Figure 14). The highest SPAD reading was at 55 DAP, 37.49 due to high chlorophyll content in the leaf and its thickness (Miah et al., 1997). The values of NDVI increased as paddy growth into different stages (Figure 15). The NDVI value at tillering stages at 23 DAP was close to zero because of low vegetation cover at this stage as the paddy leaf area was still small that only water and soil could be seen (Wang et al., 2011). As the paddy grow, the chlorophyll content increased with its ability to produce high biomass and high photosynthesis rate (Hassan et al., 2009) and influenced by the NIR absorbance.

There are three main rice phenology stages vegetation stage, reproductive stage and ripening stage (Raza et al., 2019). At vegetation stage it takes about 20 days or it can be different depending on paddy variety. The process involved in these stages is germination to panicle initiation. Paddy height, leaf area will increase gradually and active in tillering. The transition from vegetation stage to reproductive stage after the number of tillers achieved its maximum. At reproductive stage, it takes 30 days from panicle initiation to flowering and plant during this time become sensitive to stress. After flowering process, it will enter the last stage of paddy development which is ripening stage. In this stage, filling process takes place until it becomes mature. It takes about 35 days and paddy leaf become dry and turn to yellow colour. The grains are fully developed, and the upper leaves become dry and the panicle will bend downward.

\section{SPAD Value and NDVI Value Relationship}

At early growth stages, the chlorophyll content increases and absorption of light energy is close to the correlation line due to strong absorption of red and strong reflection of NIR. The high reflectance energy transmitted on the uppermost layer of the leaf and reflected from the second layer of the leaf is not fully transmitted back to the first layer of the leaf (Roy, 1989). Based on statistical analysis, the regression values between NDVI with the SPAD value, fitting $\mathrm{R}^{2}=0.4012$ (Figure 16). Meanwhile its correlation values are 0.6334 (Table 3) 
Nor Athirah Roslin, Nik Norasma Che'Ya, Rhushalshafira Rosle and Mohd Razi Ismail



Figure 14. Rice growth stages and SPAD meter values.

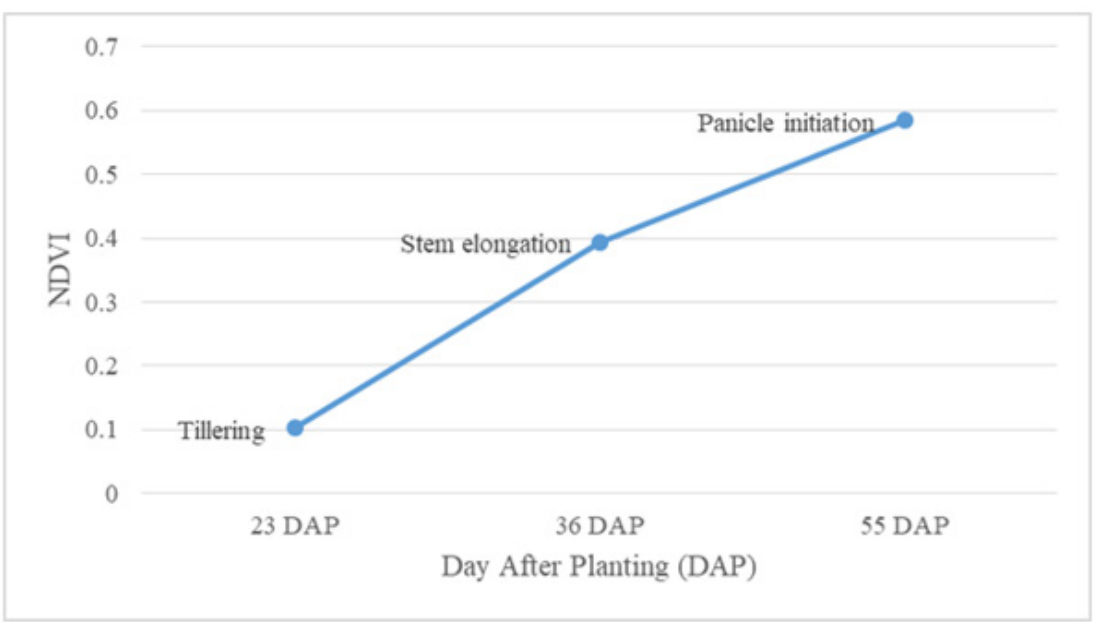

Figure 15. Rice growth stages and NDVI values.

with its root mean square error (RMSE), 0.0844. According to McHugh (2012), a correlation values ranged from 0.60 to 0.79 can be considerate as moderate with percentage of data that are reliable is $35 \%$ to $63 \%$. We were unable to obtain a higher regression and correlation values due to small number of samples size and in future research it is recommended to increase the number of samples. From the analysis, NDVI show an acceptable correlation and regression value because NDVI sensitive to detect changes in serious water shortage, nutrient deficiencies and pest or disease attack. There is strong correlation between NDVI and SPAD at the early reproductive stage and reproductive stage (Guan et al., 2019). 


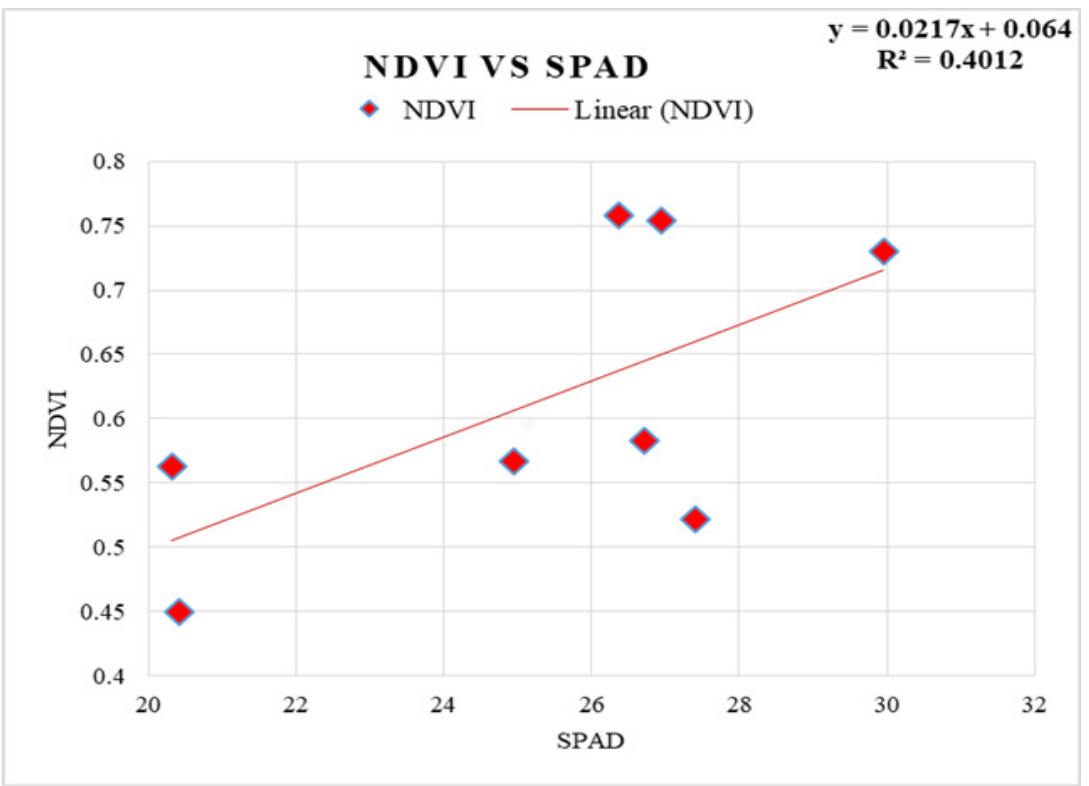

Figure 16. The regression values between SPAD with NDVI value.

Table 3

The correlation values between SPAD and NDVI

\begin{tabular}{lll}
\hline & SPAD & NDVI \\
\hline SPAD & 1 & \\
NDVI & 0.633418 & 1 \\
\hline
\end{tabular}

\section{Spatial Interpolation}

The highest predicted value represents by green colour and for the lowest predicted value in red colour. Table 4 shows spatial interpolation of NDVI map and SPAD map of study area. The value range of NDVI value at 23 DAP, 36 DAP and 55 DAP was $-0.64-0.73$, $-1-1$ and $-1-1$. The value range of the SPAD value at 23 DAP, 36 DAP and 55 DAP was $0-24,0-40$ and $0-40$.

\section{Padi2U Mobile Application}

The interface of the Padi2U smartphone app main menu successfully developed (Figure 17). Padi2U consisted of 14 menus. The different menu and their descriptions are outlined (Table 5).

Under the Drone Images menu, all the images were arranged according to the day of planting. To view the development of paddy growth for the whole season, the users just need to slide to the next image. The drone images were split into two types of images, 
namely RGB images and the map of NDVI. The index reading referred to the health status of plants and RGB images represented the true colour images for the users to compare with the NDVI map so that they could correctly identify the location (Figure 18).

Table 4

Spatial interpolation of NDVI and SPAD map

DAP NDVI map $\quad$ SPAD map

23
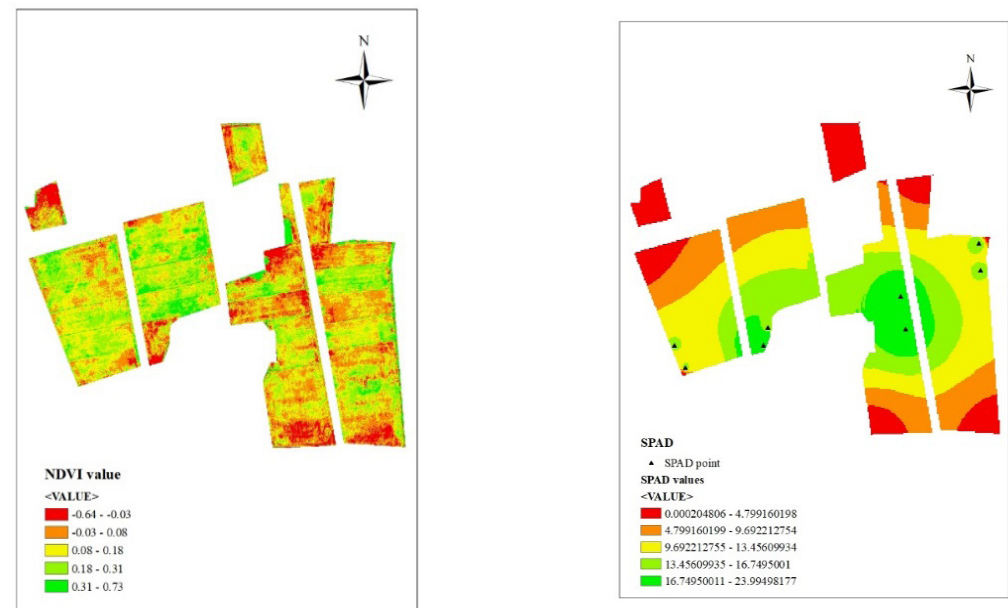

36

Table 4 (Continued)
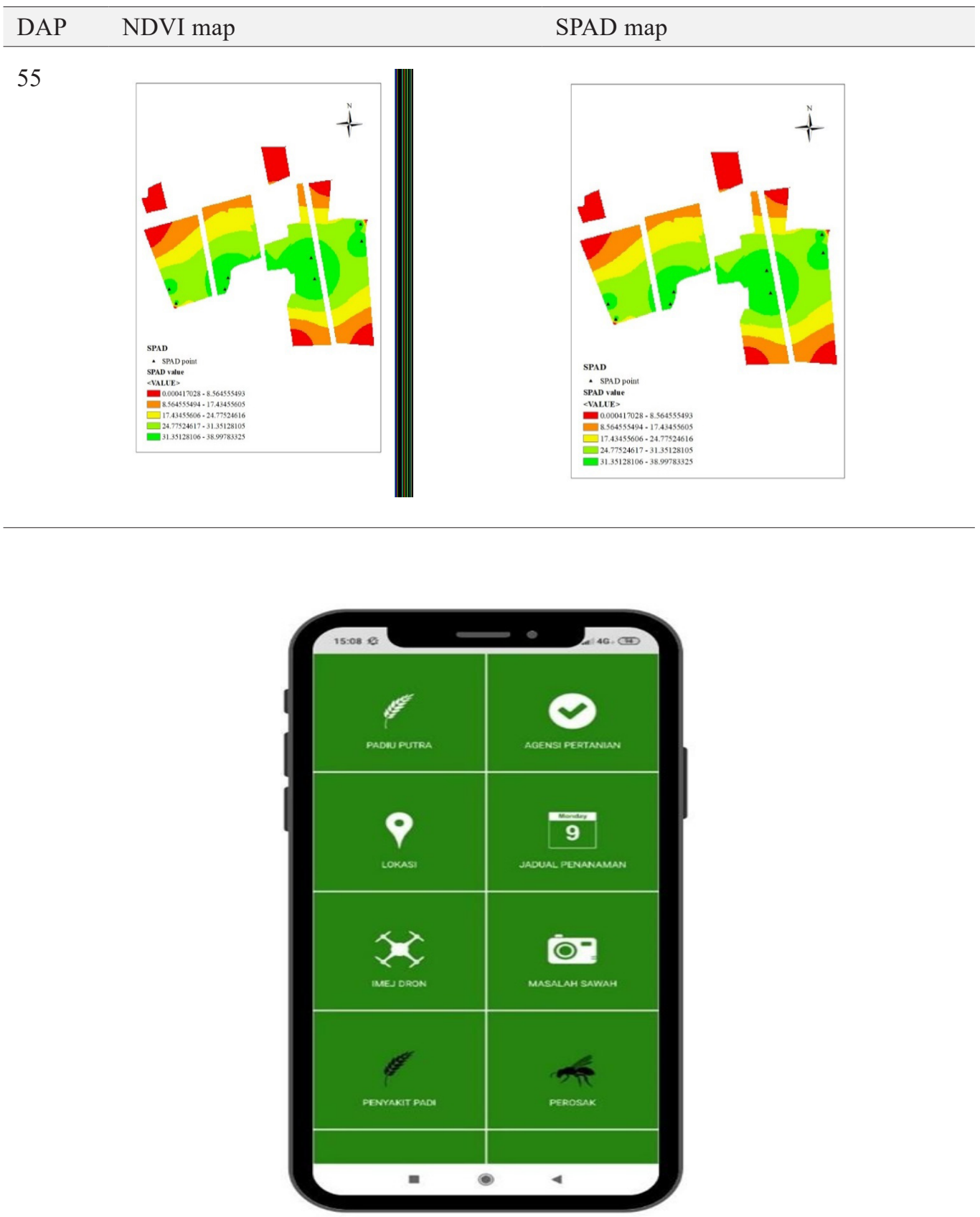

Figure 17. Main menu of Padi2U mobile app. 
Table 5

Padi2U menu description

\begin{tabular}{ll}
\hline Menu & Description \\
\hline PadiU Putra & Details about PadiU Putra \\
Agriculture Agency & Details about KADA \\
Location & Details about project site \\
Planting Schedule & Details about activity \\
Drone Images & RGB and NDVI map \\
Field Problems & Field problem images \\
Paddy Diseases & List of diseases in paddy and method to control \\
Paddy Pests & List of pests in paddy and method to control \\
Paddy Weeds & List of weeds in paddy field and method to control \\
Weather Forecast & Details about weather \\
Supplier Details & Details about agriculture supplier \\
Yield Harvested & Total of yield harvested \\
Notification & Notify user of any latest news \\
Farmer Report & User can send report about crop or field \\
\hline
\end{tabular}



Figure 18. The drone images of multispectral image and RGB images. 
Next, the pest and disease information menu provided photos of the disease, symptoms, and methods to control the disease (Figure 19). The pest images were difficult to find due to the poor weather condition and inappropriate time during the site visit. Thus, some of the images used were from reliable external sources. From the images, users were able to recognize the pest found in the field. Padi2U also provided recommendations on how to control the pest and disease in the field.

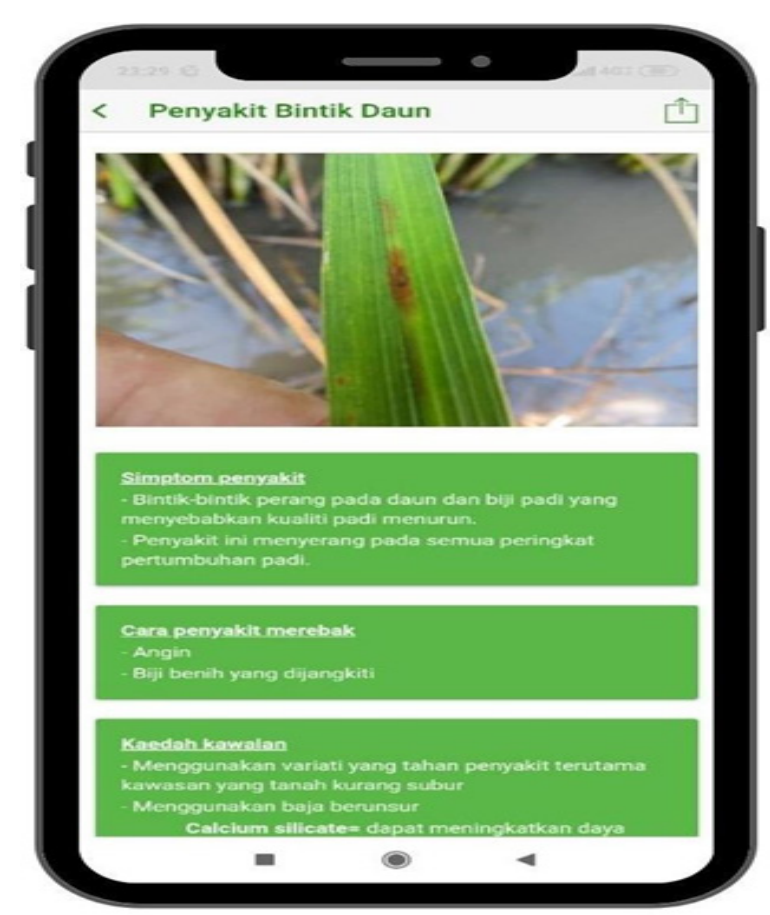

Figure 19. The symptoms caused by disease infection on the crop were shown in the app.

Lastly, the farmers could also send feedbacks or reports via the app (Figure 20). They just needed to fill in their personal information such as name before they submit the report details including photos. Therefore, Padi2U could be used by farmers and non-farmers who want to learn about agriculture and paddy crop management.

This study outlined the successful development of the Padi2U app for the Android operating system. In the future, the app can also be developed for the iOS system using the same method. The Padi2U app is different compared to existing mobile apps because it includes drone images of RGB images and multispectral images. Currently, there is no mobile app that contains drone images like Padi2U. Most of the mobile apps developed used satellite images for monitoring (Herrick et al., 2016). By comparison, images captured by drones are more realistic and clearer with higher resolution than satellite images (Khaliq 


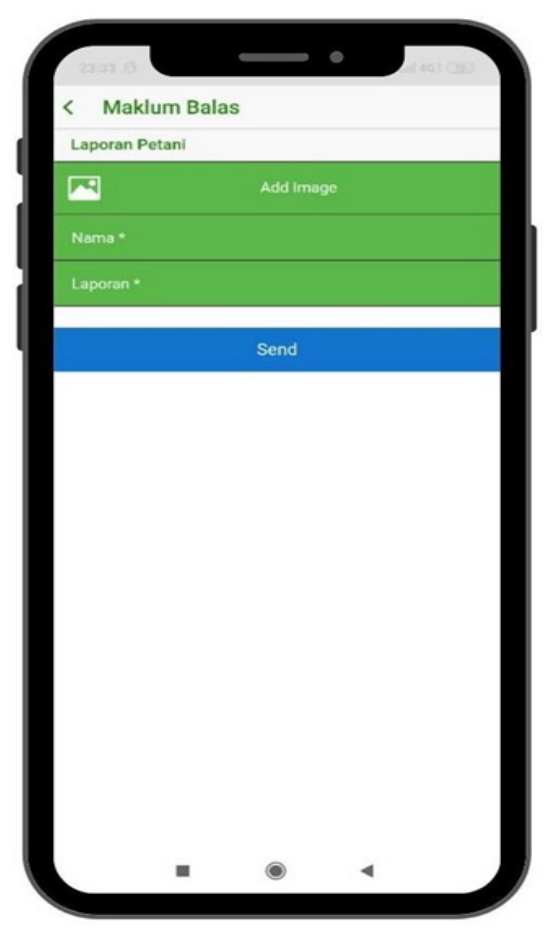

Figure 20. Farmer report form details in Padi2U app.

et al., 2019). In addition, most of the currently available mobile apps focus on one specific management aspect, such as pest and disease management (Johannes et al., 2017), irrigation system (Kodali \& Sarjerao, 2017) and soil study (Stiglitz et al., 2017). In contrast, Padi2U covers all the management aspects in paddy cultivation, including planting schedule, pest management, disease management, weed management, weather forecast, farmer report, and yield harvest information.

Nowadays, with the widespread use of the smartphone, the development of a mobile app is becoming more relevant in many sectors, including agriculture. With this, farmers can rely on faster data transmission for decision making on the management of pests and diseases. The strength of Padi2U lies within the use of the local language, thus making it more user- friendly for local farmers. Its focus on paddy and the specific area in Kelantan would be beneficial for the users from that region. Nevertheless, there are some limitations to this app. Firstly, the mobile app software requires regular updates. This can be timeconsuming and also interfere with the use until the update is complete. Secondly, it has a slow response and often lags, thus requiring further improvement on the app. Furthermore, the app is only applicable for paddy crop now. 


\section{User Acceptance Test}

The UAT was carried out using a questionnaire. A total of 13 respondents were involved in this UAT. They were from various agricultural backgrounds such as agriculture extension officers, farmers, and interns. The questionnaire was divided into two sections (section A and section B). Section A captured personal information such as occupation, age, and smartphone usage. Section B consisted of features of the Padi2U app such as the colour, information, multispectral images, and satisfaction towards the app. The results were analysed using Microsoft Excel. It showed that all the users had no problems while using the Padi2U app. Thus, satisfaction rate was 100\% (Figure 21).

Based on the result, the users showed a high percentage of satisfaction with the app. The GUI of the Padi2U app was straightforward, easy to use, and user-friendly. The farmers were also satisfied with the content regarding pests and diseases. However, they requested for the app developer to include more information about pesticides and its application in controlling pest and disease infection. Besides farmers, Padi2U can also be used by the agriculture officers. It can act as a tool to distribute and receive information in real-time. This app can also serve as a database on field information for paddy management.

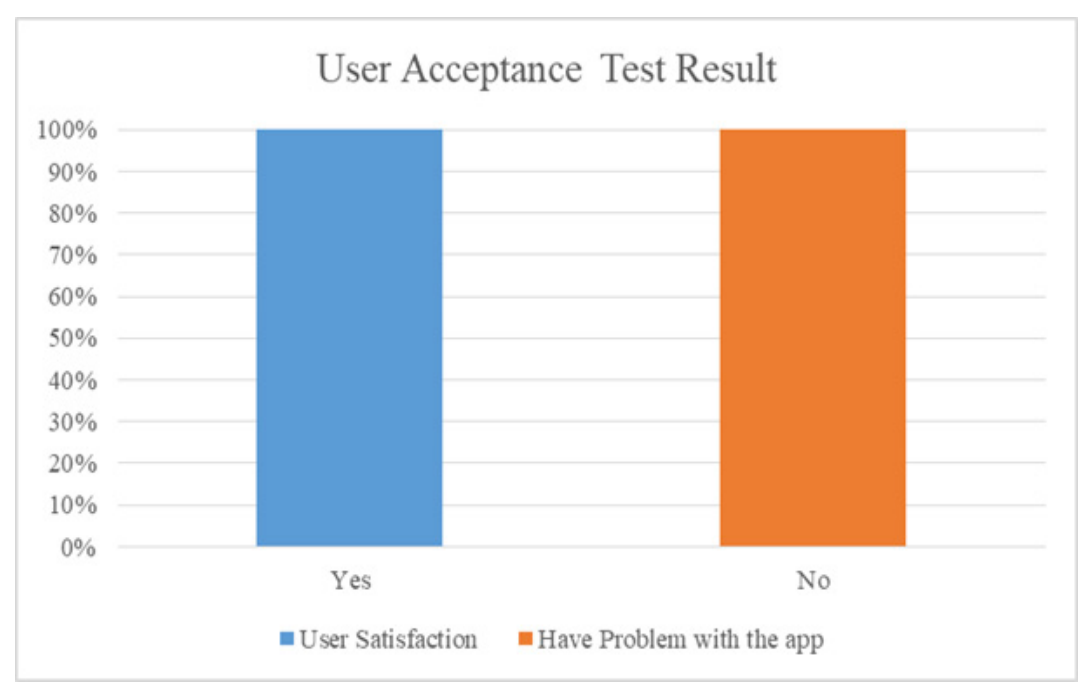

Figure 21. User Acceptance Test result showing 100\% satisfaction rate towards the Padi2U app.

\section{CONCLUSION}

In conclusion, technologies used in agriculture such as UAV and smartphone app can helped farmer to manage the crop. The multispectral UAV can be used to generate NDVI map that can assist users to monitor and manage their field in effective way by using smart phone at anywhere and anytime. The Padi2U app was successfully developed for 
paddy management based on the multispectral UAV and various data from the ground and agencies. It has a complete set of information about paddy cultivation from plantation up to harvesting. The NDVI map used in the app can assist crop growth monitoring and help farmers to increase production. Besides, farmers can overcome pest, disease, and weed problems at their farms by planning their actions based on the information in the app. This user-friendly app also makes it very convenient for the farmers to manage their paddy fields by providing information on the weather forecast, location to purchase agriculture equipment. With the 100 percentage of Padi2U acceptance by the users, this mobile app is proven to help the farmers manage their farms. By incorporating the feedbacks, Padi2U can be improved to be a better and more efficient mobile app. The use of Padi2U app will be useful to farmer and agriculture officer to manage the crop. However, this app needs realtime data of the paddy field and updated into the app. The NDVI value has correlation with the SPAD value, fitting $\mathrm{R}^{2}=0.4012$ because NDVI sensitive to detect changes in serious water shortage, nutrient deficiencies and pest or disease attack. Thus, this information can be as an indicator to farmers to regularly monitor their crop status at the field in efficient way. For recommendation, the number of samples needs to be increased in order to increase the accuracies. This limitation due to less of human resources to collect the data. Future research can apply the same method to develop a mobile app for other types of crops such as corn and pineapple.

\section{ACKNOWLEDGEMENT}

The authors would like to acknowledge the assistance by Mr. Nasir Abd. Rani and Mr. Mohd Zalyny Shah B Noh from Kemubu Agricultural Development Authority (KADA). This study also received the financial support from the Ministry of Higher Education, Malaysia under the Long-term Research Grant Scheme (LRGS) for the program titled Development of Climate Ready Rice for Sustaining Food Security in Malaysia (Vote No: 5545000) and UPM GP-IPM (Vote No: 9611400).

\section{REFERENCES}

Abdullah, S., Tahar, K. N., Rashid, M. F. A., \& Osoman, M. A. (2019). Camera calibration performance on different non-metric cameras. Pertanika Journal of Science \& Technology, 27(3), 1397-1406.

Alam, M. J., Awal, M. A., \& Mustafa, M. N. (2019). Crops diseases detection and solution system. International Journal of Electrical and Computer Engineering, 9(3), 2112-2120. https://doi.org/10.11591/ijece.v9i3. pp2112-2120

Barkunan, S. R., Bhanumathi, V., \& Sethuram, J. (2019). Smart sensor for automatic drip irrigation system for paddy cultivation. Computers \& Electrical Engineering, 73, 180-193. https://doi.org/10.1016/j. compeleceng.2018.11.013 
Bueno-Delgado, M. V., Molina-Martínez, J. M., Correoso-Campillo, R., \& Pavón-Mariño, P. (2016). Ecofert: An android application for the optimization of fertilizer cost in fertigation. Computers and Electronics in Agriculture, 121, 32-42. https://doi.org/10.1016/j.compag.2015.11.006

Casanova, D., Epema, G. F., \& Goudriaan, J. (1998). Monitoring rice reflectance at field level for estimating biomass and LAI. Field Crops Research, 55(1-2), 83-92. https://doi.org/10.1016/S0378-4290(97)00064-6

Christensen, B. M. (2019). Using mid-season NDVI data from drones to produce variable rate fertilizer maps in wheat [Master Thesis]. The North Dakota State, United States. Retrieved July 17, 2020, from https:// search.proquest.com/docview/2330627605?accountid=27932

Fatah, F. A., Yaakub, N., Ridzuan, R. M., \& Ahmad, A. R. (2017). The study on the economic fertilizer requirement for paddy production on a Malaysian soil. Journal of Fundamental and Applied Sciences, 9(2S), 777-798. https://doi.org/10.4314/jfas.v9i2s.48

Fountas, S., Carli, G., Sørensen, C. G., Tsiropoulos, Z., Cavalaris, C., Vatsanidou, A., Liakos, B., Canavari, M., Wiebensohn, J., \& Tisserye, B. (2015). Farm management information systems: Current situation and future perspectives. Computers and Electronics in Agriculture, 115, 40-50. https://doi.org/10.1016/j. compag.2015.05.011

Gamon, J. A., Field, C. B., Goulden, M. L., Griffin, K. L., Hartley, A. E., Joel, G., Penuelas, J., \& Valentini, R. (1995). Relationships between NDVI, canopy structure, and photosynthesis in three Californian vegetation types. Ecological Applications, 5(1), 28-41. https://doi.org/10.2307/1942049

Guan, S., Fukami, K., Matsunaka, H., Okami, M., Tanaka, R., Nakano, H., Sakai, T., Nakano, K., Ohdan, H., \& Takahashi, K. (2019). Assessing correlation of high-resolution NDVI with fertilizer application level and yield of rice and wheat crops using small UAVs. Remote Sensing, 11(2), Article 112. https:// doi.org/10.3390/rs11020112

Guo, J., Li, X., Li, Z., Hu, L., Yang, G., Zhao, C., Fairbairn, D., Watson, D., \& Ge, M. (2018). Multi-GNSS precise point positioning for precision agriculture. Precision Agriculture, 19(5), 895-911. https://doi. org/10.1007/s11119-018-9563-8

Hassan, M. S., Khair, A., Haque, M. M., Azad, A. K., \& Hamid, A. (2009). Genotypic variation in traditional rice varieties for chlorophyll content, SPAD value and nitrogen use efficiency. Bangladesh Journal of Agricultural Research, 34(3), 505-515. https://doi.org/10.3329/bjar.v34i3.3977

Hassan, S., Mohamed, Z. A. B., Abdullah, S. N. S., \& Zaini, N. N. (2017). Personality traits and its relationship with work performance for majority group of paddy farmers in Malaysia. Australian Academy of Business and Economics Review, 2(3), 234- 243.

Hassan, S., Yussof, N., \& Galadima, M. (2019). Farmers current agriculture practices on paddy cultivation and relationship with work performance in Iada Batang Lupar, Sarawak, Malaysia. Asian Journal of Agricultural Extension, Economics \& Sociology, 31(3), 1-14. https://doi.org/10.9734/ajaees/2019/ v31i330134 
Herrick, J. E., Beh, A., Barrios, E., Bouvier, I., Coetzee, M., Dent, D., \& Matuszak, J. (2016). The land-potential knowledge system (LandPKS): Mobile apps and collaboration for optimizing climate change investments. Ecosystem Health and Sustainability, 2(3), Article e01209. https://doi.org/10.1002/ehs2.1209

Hudzari, R. M., Ishak, W. W. W., \& Noorman, M. M. (2010). Parameter acceptance of software development for oil palm fruit maturity prediction. Journal of Software Engineering, 4(3), 244-256.

Ibrahim, A. Z., \& Alam, M. M. (2016). Climatic changes, government interventions, and paddy production: an empirical study of the Muda irrigation area in Malaysia. International Journal of Agricultural Resources, Governance and Ecology, 12(3), 292-304. https://doi.org/10.1504/IJARGE.2016.078319

Ishak, W. I. W., \& Hudzari, R. M. (2010). Image based modeling for oil palm fruit maturity prediction. Journal of Food, Agriculture \& Environment, 8(2), 469-476.

Jaiganesh, S., Gunaseelan, K., \& Ellappan, V. (2017). IOT agriculture to improve food and farming technology. In 2017 Conference on Emerging Devices and Smart Systems (ICEDSS). IEEE Conference Publication.

Johannes, A., Picon, A., Alvarez-Gila, A., Echazarra, J., Rodriguez- Vaamonde, S., Navajas, A. D., \& OrtizBarredo, A. (2017). Automatic plant disease diagnosis using mobile capture devices, applied on a wheat use case. Computers and Electronics in Agriculture, 138, 200- 209. https://doi.org/10.1016/j. compag.2017.04.013

Khaliq, A., Comba, L., Biglia, A., Ricauda Aimonino, D., Chiaberge, M., \& Gay, P. (2019). Comparison of satellite and UAV-based multispectral imagery for vineyard variability assessment. Remote Sensing, 11(4), Article 436. https://doi.org/10.3390/rs11040436

Khanna, A., \& Kaur, S. (2019). Evolution of Internet of Things (IoT) and its significant impact in the field of precision agriculture. Computers and Electronics in Agriculture, 157, 218-231. https://doi.org/10.1016/j. compag.2018.12.039

Kodali, R. K., \& Sarjerao, B. S. (2017). A low cost smart irrigation system using MQTT protocol. In 2017 IEEE Region 10 Symposium (TENSYMP). IEEE Conference Publication.

Kularbphettong, K., Phoso, W., \& Roonrakwit, P. (2019). The Automation of Mobile Application to Manage the Rice Fields. TEM Journal, 8(3), 866-871.

Liu, C., Liu, Y., Lu, Y., Liao, Y., Nie, J., Yuan, X., \& Chen, F. (2019). Use of a leaf chlorophyll content index to improve the prediction of above- ground biomass and productivity. Peer J, 6, Article e6240. https:// doi.org/10.7717/peerj.6240

Liu, S., Li, L., Gao, W., Zhang, Y., Liu, Y., Wang, S., \& Lu, J. (2018). Diagnosis of nitrogen status in winter oilseed rape (Brassica napus L.) using in-situ hyperspectral data and unmanned aerial vehicle (UAV) multispectral images. Computers and Electronics in Agriculture, 151, 185-195. https://doi.org/10.1016/j. compag.2018.05.026

Majid, K., Herdiyeni, Y., \& Rauf, A. (2013). I-PEDIA: Mobile application for paddy disease identification using fuzzy entropy and probabilistic neural network. In 2013 International Conference on Advanced Computer Science and Information Systems (ICACSIS). IEEE Conference Publication.

Manso, G. L., Knidel, H., Krohling, R. A., \& Ventura, J. A. (2019). A smartphone application to detection and classification of coffee leaf miner and coffee leaf rust. Computer Vision and Pattern Recognition, 1-36. 
McHugh, M. L. (2012). Interrater reliability: The kappa statistic. Biochemia Medica, 22(3), 276-282.

Miah, M. N. H., Yoshida, T., \& Yamamoto, Y. (1997). Effect of nitrogen application during ripening period on photosynthesis and dry matter production and its impact on yield and yield components of semidwarf iniica rice varieties under water culture conditions. Soil Science and Plant Nutrition, 43(1), 205-217. https://doi.org/10.1080/00380768.1997.10414728

Muangprathub, J., Boonnam, N., Kajornkasirat, S., Lekbangpong, N., Wanichsombat, A., \& Nillaor, P. (2019). IoT and agriculture data analysis for smart farm. Computers and Electronics in Agriculture, 156, 467-474. https://doi.org/10.1016/j.compag.2018.12.011

Mwebaze, E., \& Owomugisha, G. (2016). Machine learning for plant disease incidence and severity measurements from leaf images. In 2016 15th IEEE international conference on machine learning and applications (ICMLA). IEEE Conference Publication.

Nam, W. H., Kim, T., Hong, E. M., Choi, J. Y., \& Kim, J. T. (2017). A wireless sensor network (WSN) application for irrigation facilities management based on Information and Communication Technologies (ICTs). Computers and Electronics in Agriculture, 143, 185-192. https://doi.org/10.1016/j.compag.2017.10.007

Nasir, H., Aris, A. N., Lajis, A., Kadir, K., \& Safie, S. I. (2018). Development of android application for pest infestation early warning system. In 2018 IEEE 5th International Conference on Smart Instrumentation, Measurement and Application (ICSIMA) (pp. 1-5). IEEE Conference Publication.

Norasma, C. Y. N., Fadzilah, M. A., Roslin, N. A., Zanariah, Z. W. N., Tarmidi, Z., \& Candra, F. S. (2019). Unmanned aerial vehicle applications in agriculture. In IOP Conference Series: Materials Science and Engineering. Aceh, Indonesia. IOP Publishing.

Raza, S. M. H., Mahmood, S. A., Gillani, S. A., Hassan, S. S., Aamir, M., Saifullah, M., Basheer, M., Ahmad, A., Rehman, S. U., \& Ali, T. (2019). Estimation of net rice production by remote sensing and multi source datasets. Sarhad Journal of Agriculture, 35(3), 955-965. https://doi.org/10.17582/journal. sja/2019/35.3.955.965

Razali, M. H., Ismail, W. I. W., Ramli, A. R., Sulaiman, M. N., \& Harun, M. H. (2009). Development of image based modeling for determination of oil content and days estimation for harvesting of fresh fruit bunches. International Journal of Food Engineering, 5(2), 1633-1637.

Rosle, R., Che'Ya, N. N., Roslin, N. A., Halip, R. M., \& Ismail, M. R. (2019). Monitoring early stage of rice crops growth using normalized difference vegetation index generated from UAV. In IOP Conference Series: Earth and Environmental Science. Sulawesi, Indonesia. IOP Publishing.

Roy, P. S. (1989). Spectral reflectance characteristics of vegetation and their use in estimating productive potential. Plant Sciences, 99(1), 59-81. https://doi.org/10.1007/BF03053419

Siahaan, A. P. U., \& Wijaya, R. F. (2018). Smart farmer application in monitoring and learning of android-based rice cultivation. International Journal of Scientific Research in Science and Technology 4(11), 16-20. https://doi.org/10.32628/IJSRST1840115

Simorangkir, G. D., Sarwoko, E. A., Sasongko, P. S., \& Endah, S. N. (2018). Usability testing of corn diseases and pests detection on a mobile application. In 2018 2nd International Conference on Informatics and Computational Sciences (ICICoS). IEEE Conference Publication. 
Stiglitz, R., Mikhailova, E., Post, C., Schlautman, M., Sharp, J., Pargas, R., Glover, B., \& Mooney, J. (2017). Soil color sensor data collection using a GPS- enabled smartphone application. Geoderma, 296, 108-114. https://doi.org/10.1016/j.geoderma.2017.02.018

Sushanth, G., \& Sujatha, S. (2018). IOT based smart agriculture system. 2018 International Conference on Wireless Communications, Signal Processing and Networking (WiSPNET). IEEE Conference Publication.

Valdez-Morones, T., Pérez-Espinosa, H., Avila-George, H., Oblitas, J., \& Castro, W. (2018). An android app for detecting damage on tobacco (Nicotiana tabacum L.) leaves caused by blue mold (Penospora tabacina Adam). In 2018 7th International Conference On Software Process Improvement (CIMPS). IEEE Conference Publication.

Vesali, F., Omid, M., Kaleita, A., \& Mobli, H. (2015). Development of an android app to estimate chlorophyll content of corn leaves based on contact imaging. Computers and Electronics in Agriculture, 116, 211220. https://doi.org/10.1016/j.compag.2015.06.012

Wang, F. M., Huang, J. F., \& Lou, Z. H. (2011). A comparison of three methods for estimating leaf area index of paddy rice from optimal hyperspectral bands. Precision Agriculture, 12(3), 439-447. https://doi. org/10.1007/s11119-010-9185-2

Watcharabutsarakham, S., Methasate, I., Watcharapinchai, N., Sinthupinyo, W., \& Sriratanasak, W. (2016). An approach for density monitoring of brown planthopper population in simulated paddy fields. In 2016 13th International Joint Conference on Computer Science and Software Engineering (JCSSE) (pp. 1-4). IEEE Conference Publication.

Yusof, Z. M., Misiran, M., Baharin, N. F., Yaacob, M. F., Aziz, N. A. B. A., \& Sanan, N. H. B. (2019). Projection of Paddy Production in Kedah Malaysia: A Case Study. Asian Journal of Advances in Agricultural Research, 1-6. https://doi.org/10.9734/ajaar/2019/v10i330030

Yuzugullu, O., Marelli, S., Erten, E., Sudret, B., \& Hajnsek, I. (2017). Determining rice growth stage with X-band SAR: A metamodel based inversion. Remote Sensing, 9(5), Article 460. https://doi.org/10.3390/ rs9050460

Zhang, F., \& Cao, N. (2019). Application and research progress of geographic information system (GIS) in agriculture. In 2019 8th International Conference on Agro-Geoinformatics (Agro-Geoinformatics) (pp. 1-5). IEEE Conference Publication. 